\title{
Effect of Margin Level Setting in Abutments Created by CAD/CAM on Residual Cement
}

Yusuke Taniguchi $^{1}$, Kae Kakura ${ }^{1}$, Takashi Tsuzuki ${ }^{1}$, Masahide Baba ${ }^{1,2}$, Ippei Hamanaka ${ }^{1}$, Tomohiro Kawaguchi ${ }^{1}$, Masahiro Yoneda ${ }^{3^{*}}$ and Hirofumi Kido ${ }^{1}$

${ }^{1}$ Department of Oral Rehabilitation, Fukuoka Dental College, Japan

${ }^{2}$ Fukuoka Oral Implant Research Association, Japan

${ }^{3}$ Section of General Dentistry, Department of General Dentistry, Fukuoka Dental College, Japan

*Corresponding author: Masahiro Yoneda, Section of General Dentistry, Department of General Dentistry Fukuoka Dental College, Japan, Tel: 81-92-801-0411/81-92-801-0165; Fax: 81-92-801-4909; E-mail: yoneda@college.fdcnet.ac.jp

Received date: November 21, 2018; Accepted date: November 28, 2018; Published date: December 01, 2018

Copyright: (c) 2018 Taniguchi Y, et al. This is an open-access article distributed under the terms of the Creative Commons Attribution License, which permits unrestricted use, distribution, and reproduction in any medium, provided the original author and source are credited.

\begin{abstract}
Background: Various complications of dental implants have been reported as cases with long-term implant use increase with its spread of use. It has been reported that residual cement is involved in approximately $80 \%$ of the peri-implantitis cases, and prompt management of residual cement is important. This study examined cementation of the superstructure and how the level of gingival margin of abutments affected the amount of residual cement. The study also examined the level of abutment margin to avoid residual cement.

Materials and Methods: Working models were prepared using epoxy resin. Implants were placed in one part of the maxillas. Silicone rubber was used to simulate peri-implant gingiva. Morphological designing was performed for the abutments and superstructures on the prepared models. The examination was performed on four levels of abutment margins: the same level as the margin of the gingiva (ML0), $1 \mathrm{~mm}$ subgingival (ML-1), $2 \mathrm{~mm}$ subgingival (ML-2), and $3 \mathrm{~mm}$ subgingival (ML-3). Temporary cement was placed in each superstructure which was then placed on the abutment. An access hole was created on the superstructure, and the abutment and superstructure were removed from the model. Observations were made on the cement remaining subgingivally (residual cement). The cement above the margin and residual cement were collected.
\end{abstract}

Results: If the margin level was subgingival, there was a tendency for residual cement to adhere to the entire subgingival area regardless of the margin depth. The residual cement weight percentage was significantly higher for the ML-2 and ML-3 margins than for ML-0 margins. The percentages of supragingival cement did not differ significantly among different abutment margins.

Discussion and Conclusion: The results of this study suggest that when the abutment margin is ML-2 or lower, the cement does not extrude supragingivally and tends to remain subgingivally.

Keywords: Residual cement; Abutment margin; CAD/CAM; Periimplantitis; Peri-implant gingiva

\section{Introduction}

Peri-implantitis, a condition similar to periodontitis, is likely to occur with implants because soft tissue sealing of implant necks is weaker than with natural teeth [1], and a relatively high incidence periimplantitis has already been reported [2,3]. Peri-implantitis is generally attributed to insufficient cleaning around the implant and excessive occlusal load, and maintenance that involves peri-implant cleaning and occlusal management are considered essential for prevention of periimplantitis.

Cemented superstructures are widely used clinically in implant prostheses [4], but it has been noted that cemented superstructures are detrimental to peri-implant tissue because of the problem of excessive residual cement [5]. Various studies of excessive residual cement have been conducted, and it has been suggested that peri-implantitis caused by residual cement may have a much higher incidence than previously thought [3].
Therefore, this study investigated the amount of residual cement in environments with different margin levels between the superstructure and a series of abutments with uniform shapes designed by CAD/ CAM.

\section{Material and Methods}

\section{Experimental mold}

An epoxy resin mold (Tamiya Clear epoxy resin, Tamiya, Inc., Shizuoka, Japan) was used as the experimental mold. An implant analog (Nobel Active RP, Nobel Biocare) was placed in the maxillary left incisor position, and gingival tissue was reproduced using gum silicone around the implant analog platform. The implant analog platform was positioned vertically $5 \mathrm{~mm}$ below the buccal gingival margin, $3.5 \mathrm{~mm}$ below the palatal gingival margin, $7 \mathrm{~mm}$ below the mesial margin, and $6 \mathrm{~mm}$ below the distal gingival margin (Figure 1). The implant analog was positioned horizontally so that the line connecting the palatal necks of the two adjacent teeth was tangential to the platform circumference (Figure 2). 


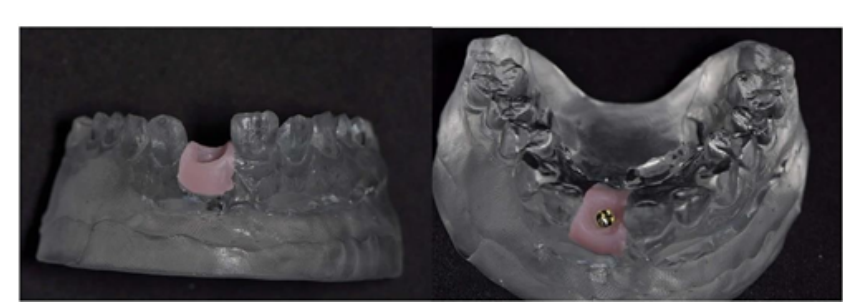

Figure 1: Working model with implant analog and gingiva.

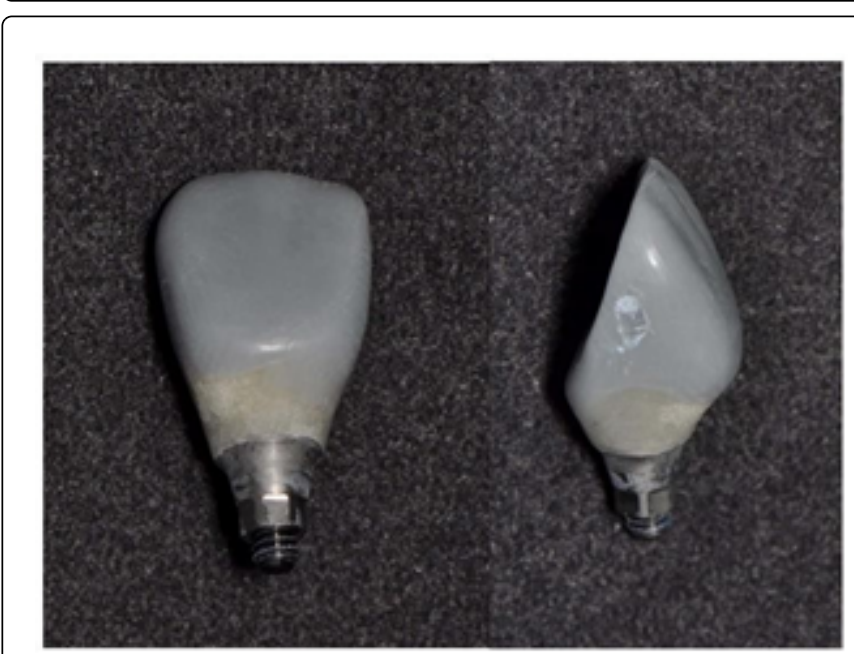

Figure 2: The entire shape including the upper structure was the same for all templates.

\section{CAD/CAM abutments}

A wax-up on the experimental mold was performed using a temporary superstructure abutment (Temporary Abutment Engaging Conical Connection, Nobel Biocare). The wax pattern of the superstructure was scanned with a non-contact laser scanner $\left(\right.$ NobelProcera $\left.^{\circ}\right)$.

Genion scanner, Nobel Biocare), and experimental abutments were designed by CAD. Experimental abutments were fabricated with four levels of abutment margins: a margin at the same height as the gingival margin of the experimental model (ML0), a margin $1 \mathrm{~mm}$ lower (ML-1), a margin $2 \mathrm{~mm}$ lower (ML-2), and a margin $3 \mathrm{~mm}$ lower (ML-3). Titanium blocks (Ti6Al4V medical titanium) were cut with a milling machine (NobelProcera ${ }^{\oplus}$, Nobel Biocare) to fabricate the experimental abutments (Figure 3). An experimental superstructure for each abutment was fabricated using self-curing resin (Unifast ${ }^{\circ} \mathrm{III}$, GC Japan).

\section{Cement fixation of the superstructure}

The interior surface of each experimental superstructure was filled with temporary cement (HY-Bond ${ }^{\oplus}$ temporary cement, Shofu Ltd.), and applied by hand pressure to the corresponding abutment that was fixed in the experimental mold. After the cement had cured completely, all supragingival cement was carefully removed and collected (Figure 4).

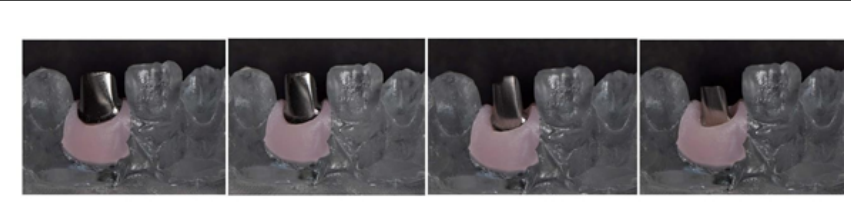

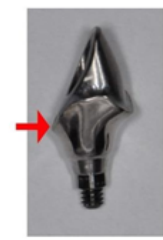

A

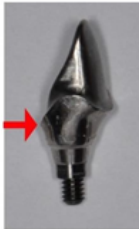

B

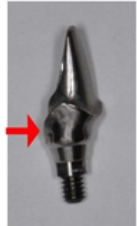

C

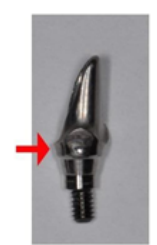

D
Figure 3: Four levels of abutment margins were created using CAD/ CAM.

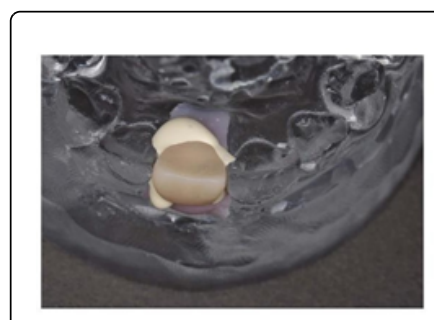

A

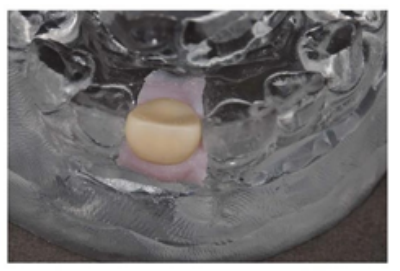

B
Figure 4: Supragingival cement was removed.

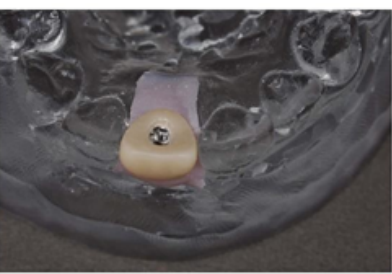

A

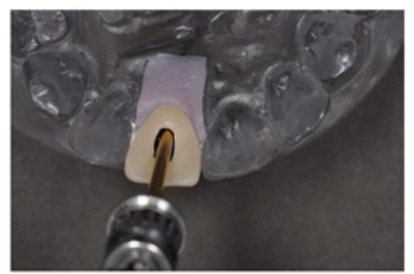

B
Figure 5: Abutment and supretstructure were removed from the model.

The lingual face of the superstructure was drilled to form an access hole, the abutment screw was loosened, and the superstructure together with excess cement was extracted. The attached cement that remained below the gingival margin (residual cement) was observed (Figure 5), and all residual cement was collected. The supragingival cement and residual cement were weighed separately on an analytical balance (GR-200, A and D Co., Ltd.), and the ratio of residual cement to total cement was calculated.

\section{Statistical analysis}

Samples were weighed 3 times and the average values were calculated. SPSS ver. 19 (SPSS Inc., Chicago, IL) was used for the statistical analysis. A significant difference was tested using Student's ttest and two-way ANOVA, and then Bonferroni's post hoc test was performed. The level of significance was set at $\mathrm{P}<0.05$. 
Citation: Taniguchi Y, Kakura K, Tsuzuki T, Baba M, Hamanaka I, et al. (2018) Effect of Margin Level Setting in Abutments Created by CAD/CAM on Residual Cement. Dentistry 8: 520. doi:10.4172/2161-1122.1000520

Page 3 of 5

\section{Result}

\section{Observation of cement attachment}

As the margin level became deeper, the amount of residual cement attached below the margin tended to increase. Furthermore, the amount of supragingival cement tended to decrease as the margin level became deeper (Figures 6-9).

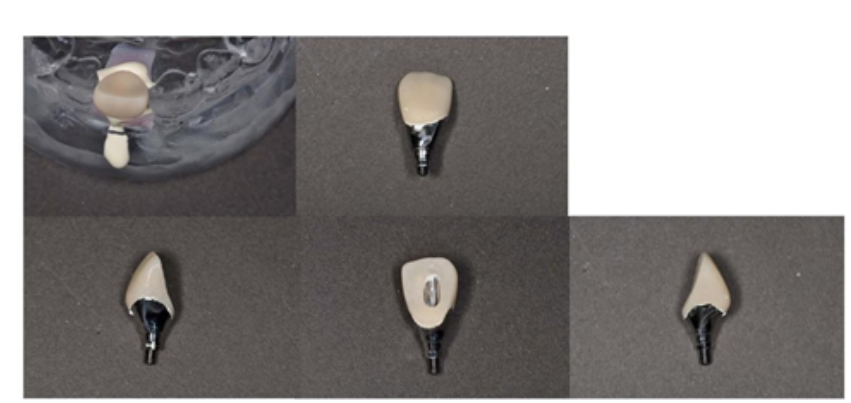

Figure 6: ML0.

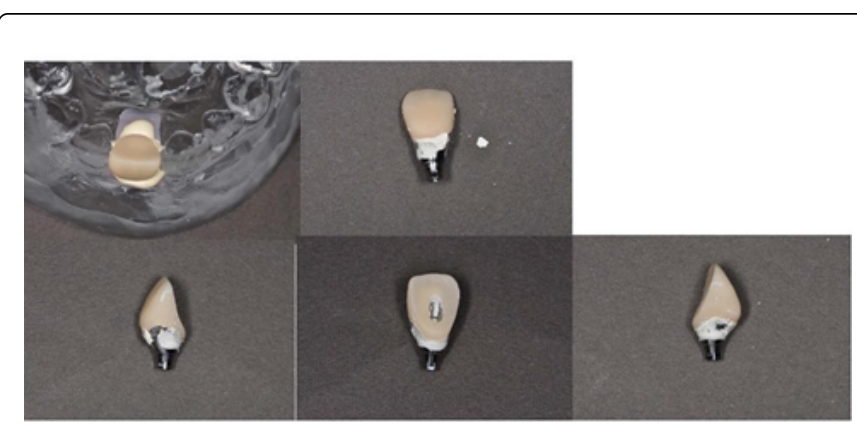

Figure 7: ML-1.

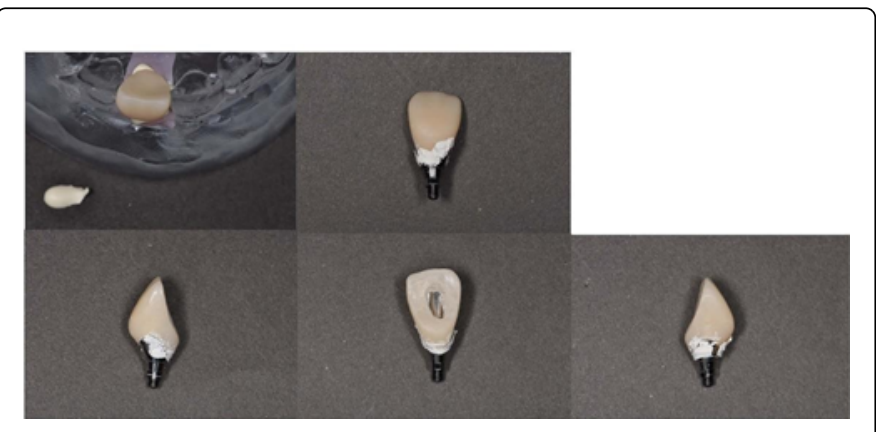

Figure 8: ML-2.

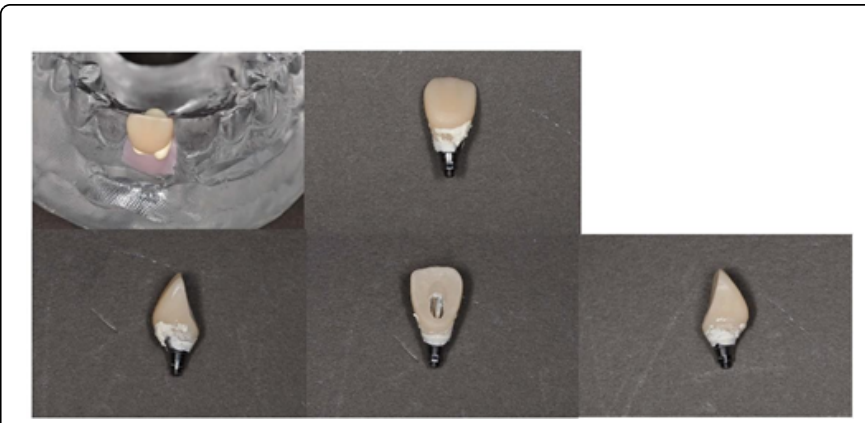

Figure 9: ML-3.

\section{Residual cement ratio}

The ratios of residual cement for both margins ML-2 and ML-3 were significantly greater than the ratio for ML0 (Figure 10). No significant differences were found in the ratios of cement above the margin relative to the difference in abutment margin level (Figure 11).

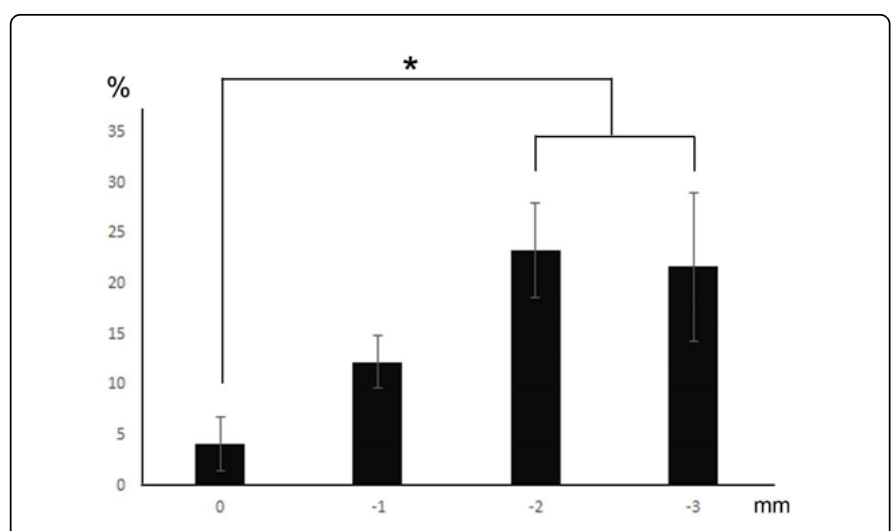

Figure 10: Residual cement was compared among the abutment margin levels. ${ }^{*} \mathrm{P}<0.05$, compared with the corresponding value for the abutment margin level was $2 \mathrm{~mm}$ or less $(\mathrm{n}=3)$.

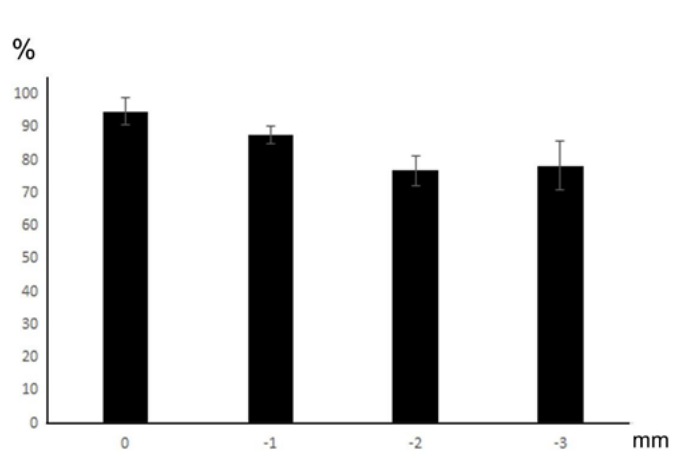

Figure 11: Cement above the margin was compared among the abutment margin levels. 


\section{Discussion}

Obtaining osseointegration by modifying the surface texture of the implant has become relatively easy. However, the question of how long healthy osseointegration can be sustained is important for the longterm success of implant treatment. Peri-implantitis is the greatest factor in preventing the long-term success of implant treatment. Poor peri-implant hygiene and excessive occlusal load have been noted as causes of peri-implantitis. Many articles on the relationship between oral hygiene and peri-implantitis have been published, and Karoussis, et al. [6] further report that patients with a history of the periodontal disease have a high incidence of peri-implantitis. Meanwhile, Tomas and colleagues [7] studied how a history of periodontal disease and superstructure fixation method affect the onset of peri-implantitis. They found that among patients with a history of periodontal disease, $85 \%(62 / 73)$ of implants diagnosed with peri-implantitis had cement fixation and $2 \%(2 / 185)$ had screw fixation; and among patients without a history of periodontal disease, 30\% (17/56) of implants diagnosed with peri-implantitis had cement fixation and $0 \%(0 / 53)$ had screw fixation. Moreover, Korsch, et al. [8] reported that removing cement reduces inflammation in peri-implantitis resulting from excess residual cement. These findings suggest that not only a history of periodontal disease and the state of oral hygiene but also excess residual cement that provides a foothold for plaque and bacteria may strongly affect the onset of peri-implantitis.

In this study, we found that if the abutment margin level is set deeper than $2 \mathrm{~mm}$ below the gingival margin, the ratio of excess residual cement increases significantly. Linkevicius, et al. [9] reported that in experimental abutments fabricated by casting, the amount of excess residual cement increases when the margin level is set deeper than $2 \mathrm{~mm}$ below the gingival margin. In that experiment, however, the shape of the subgingival contour was clearly different for each abutment because the abutments were made by casting. Therefore, in this study, we used titanium abutments fabricated by CAD/CAM, which has been incorporated clinically in recent years and thereby unified the subgingival contour and shape of the superstructure. This study and the study by Linkevicius, et al. [9] differ in factors that are thought to have a major effect on the amount of excess residual cement such as the silicone rubber material used in this study as well as its shape and mechanical properties, a uniform abutment shape, and a different type of cement. Despite these differences, we also found a significantly greater amount of residual cement at abutment margins of $2.0 \mathrm{~mm}$ or more below the gingival margin. These findings strongly suggest that with a cement-fixed superstructure implant, the level of the abutment margin should be shallower than $2.0 \mathrm{~mm}$ below the gingival margin to prevent excess residual cement and protect against future peri-implantitis. Moreover, Ager, et al. [10] showed that removal becomes impossible when the abutment margin level is $1.5 \mathrm{~mm}$ or more below the gingival margin, and that forced attempts to remove the cement will damage the abutment.

In this study, the shapes of the superstructures and abutments were unified. Therefore, when the abutment margin level was set deeper, the abutment diameter was smaller, the height was lower, and the total amount of cement within the superstructure was smaller. Even so, it became clear that when the abutment margin position becomes too deep, the amount of excess residual cement increases significantly. In addition, the relationship between the amount of excess residual cement and the depth of the abutment margin level is not proportional, and our findings indicate that if the depth of the margin exceeds a certain level, the amount of residual cement sharply increases.
As a method of decreasing excessive residual cement, Santosa, et al. [11] reported that the amount can be reduced by using an abutment replica before attaching the superstructure to the abutment to reduce the amount of residual cement on the inner surface of the superstructure as much as possible. Moreover, Walfart, et al. [12] reported that when superstructures were mounted on abutments with cement, no significant difference in bonding strength was found whether the cement was applied over the whole inner surface of the superstructure or only applied up halfway from the margin. These findings suggest that by adjusting the amount of cement, the risks involved with excess residual cement can be reduced without compromising retention.

Behr, et al. [13] compared the ease of removing excess residual cement in a modeling experiment using titanium and zirconia abutments. They report that excess residual cement can be removed more easily from a zirconia abutment than from a titanium abutment. From this finding, it appears that the choice of abutment material is also effective in reducing excess residual cement.

The difference in anatomical structure between implants and natural teeth has been noted as a factor that makes it easier for the cement to remain around an implant. Natural teeth have connective tissue attached where the teeth pass through the gingiva and strong soft tissue sealing, so cement is unlikely to infiltrate to any great depth. With an implant, however, the epithelium is only weakly attached, so the cement infiltrates easily [14]. In addition, recently the number of systems that use platform switching in implant treatment to prevent peri-implant bone resorption has increased [15], and the implantation depth tends to be getting deeper. Cement will penetrate deeper and remain if the implantation depth increases, and increased depth is likely to cause peri-implantitis.

\section{Conclusion}

The results of this study suggest that if the abutment margin level is deeper than $2 \mathrm{~mm}$ below the gingival margin, the cement will not be expelled and is likely to remain below the gingival margin. Because this experiment has the limitation of using a model, we believe that further research is needed on topics such as the effect of differences in elasticity of the artificial gingiva, and actual in vivo proof of concept.

\section{Authors Contributions}

- Yusuke Taniguchi (Research Associate): Concept, data collection, and analysis revising article

- Kae Kakura (Lecturer): Data collection and analysis, revising article

- Takashi Tsuzuki (Assistant professor): Data analysis, revising article

- Masahide Baba (Medical staff member): Data analysis, revising article

- Ippei Hamanaka (Research Associate): Data analysis, revising article

- Tomohiro Kawaguchi (Lecturer): Data collection and analysis, revising article

- Masahiro Yoneda (Professor): Concept and design, revising article

- Hirofumi Kido (Professor): Concept and design, revising article

The eight authors listed above approved the present version of the manuscript and agreed on accountability for all aspects of the work. 
Citation: $\quad$ Taniguchi Y, Kakura K, Tsuzuki T, Baba M, Hamanaka I, et al. (2018) Effect of Margin Level Setting in Abutments Created by CAD/CAM on Residual Cement. Dentistry 8: 520. doi:10.4172/2161-1122.1000520

Page 5 of 5

\section{Conflict of Interest}

This study was not supported by any company and all the authors have no conflict of interest.

\section{References}

1. Wadhwani C, Rapoport D, La Rosa S, Hess T, Kretschmar S (2012) Radiographc detection and characteristic patterns of residual excess cement associated with cement-retained implant restorations: a clinical report. J Prosthet Dent 107: 151-157.

2. Papaspyridakos P, Chen CJ, Chuang SK, Weber HP, Gallucci GO (2012) A systematic review of biologic and technical complications with fixed implant rehabilitations for edentulous patients. Int J Oral Maxillofac Implants 27: 102-110.

3. Wilson TG Jr (2009) The positive relationship between excess cement and peri-implant disease: a prospective clinical endoscopic study. J Periodontol 80: 138-192.

4. Jung RE, Pjetursson BE, Glauser R, Zembic A, Zwahlen M, et al. (2008) A Systematic review of the 5-year survival and complication rates of implant-supported single crowns. Clin Oral Implant Res 19: 119-130.

5. Wittneben JG, Joda T, Weber HP, Brägger U (2017) Screw retained vs. cement retained implant-supported fixed dental prosthesis. Periodontol 73: 141-151.

6. Karoussis IK, Salvi GE, Heitz-Mayfield LJ, Brägger U, Hämmerle CH, et al. (2003) Long-term implant prognosis in patients with and without a history of chronic periodontitis: a 10-year prospective cohort study of the ITI dental implant system. Clin Oral Implants Res 14: 329-339.

7. Linkevicius T, Puisys A, Vindasiute E, Linkeviciene L, Apse P (2013) Dose residual cement around implant-supported restorations cause peri- implant disease? A retrospective case analysis. Clin Oral Implants Res 24: 1179-1189.

8. Korsch M, Robra BP, Walther W (2015) Cement-assocciated signs of inflammation: Retrospective analysis of the effect of excess on pri-implant tissue. Int J Prosthodont 28:11-18.

9. Linkevicius T, Vindasiute E, Puisys A, Peciuliene V (2011) The influence of margin location on the amount of undetected cement excess after delivery of cement-retained implant restorations. Clin Oral Implants Res 22: 1379-1384.

10. Ager JR, Cameron SM, Hughbanks JC, Parker MH (1997) Cement removal from restorations luted to titanium abutments with simulated subgingival margins. J Prosthet Dent 78: 43-47.

11. Santosa RE, Martin W, Morton D (2010) Effects of a cementing technique in addition to luting agent on the uniaxial retention force of a single-tooth implant-supported restoration: an in vitro study. Int J Oral Maxillofac Implants 25: 1145-1152.

12. Walfart M, Wolfart S, Kern M (2006) Retention forces and seating discrepancies of implant-retained castings after cementation. Int J Oral Maxillofac Implants 21: 519-525.

13. Behr M, Spitzer A, Preis V, Weng D, Gosau M, et al. (2014) The extent of luting agent remnants on titanium and zirconia abutment analogs after scaling. Int J Oral Maxillofac Implant 29: 1185-1192.

14. Canullo L, Bignozzi I, Cocchetto R, Cristalli MP, Iannello G (2010) Immediate positioning of a definitive abutment versus repeated abutment replacements in postextractive implants: 3-year follow-up of a randomized multicentre clinical trial. Eur J Oral Implantol 3: 285-296.

15. Lazzara RJ, Porter SS (2006) Platform switching: a new concept in implant dentistry for controlling postrestorative crestal bone levels. Int J Periodontics Restorative Dent 26: 9-17. 